\title{
COMPARISON OF THE ROLE OF FOUR DIFFERENT CARBIDES IN THE HYDROGEN INDUCED MECHANICAL DEGRADATION OF LAB CAST FE-C-X ALLOYS
}

\author{
T. DEPOVER \\ Department of Materials Science \\ and Engineering, Ghent University \\ (UGent), Technologiepark 903, B- \\ 9052 Ghent, Belgium
}

\author{
K. VERBEKEN \\ Department of Materials Science \\ and Engineering, Ghent University \\ (UGent), Technologiepark 903, B- \\ 9052 Ghent, Belgium
}

\begin{abstract}
The present work evaluates hydrogen trapping and hydrogen induced ductility loss of four lab cast Fe-C-X martensitic Q\&T alloys. Ti, Mo, Cr and V are used as ternary alloying elements. The materials are compared in two conditions: as$\mathrm{Q}$ and Q\&T. Tensile tests are performed to evaluate $\mathrm{H}$ induced mechanical degradation. The hydrogen trapping capacity of the precipitates is investigated by TDS, while hot/melt extraction is done to determine the amount of hydrogen. A correlation between the degree of hydrogen induced mechanical degradation and the amount of hydrogen trapped by dislocations was observed.
\end{abstract}

\section{INTRODUCTION}

In steel alloy development, the role of carbides has been a relevant topic [1]. They are also often cited to be beneficial as efficient $\mathrm{H}$ trapping sites. Although TDS studies showed the $\mathrm{H}$ trapping ability of several carbides [2-9], literature relating their impact on the mechanical properties in the presence of $\mathrm{H}$ is limited $[10,11]$. However, steels with an increased strength level are considered to be prone to HE [12-14]. The interaction of these high strength steels with $\mathrm{H}$ has been studied thoroughly during the last decade $[15,16]$. Recently, our group presented some results on four industrial multiphase high strength steels [17-22]. The mechanical properties were investigated as well [14] and a significant $\mathrm{H}$ induced ductility loss was observed, except for the HSLA (high strength low alloy) steel, which was attributed to the presence of $\mathrm{Ti}$ - and $\mathrm{Nb}$ - carbo-nitrides.

Recently, more and more emphasis is put on the addition of carbides as $\mathrm{H}$ trapping sites. Generally, trapping diffusible $\mathrm{H}$ using nano-sized carbides as $\mathrm{H}$ traps is one of the main strategies to enhance the resistance against HE [10, 14, 23]. However, the complex microstructure of multiphase steels hinders interpreting $\mathrm{H}$ related observations. Recently, we discussed specifically designed Fe-C-X alloys containing carbide forming elements, i.e. $\mathrm{X}=\mathrm{Ti}, \mathrm{Cr}$, Mo and $\mathrm{V}$ [24-27]. However, each paper focused on one specific type of carbide forming element. The present study aims at making comparison between the different carbides. 


\section{EXPERIMENTAL PROCEDURE}

Four different steel grades with a stoichiometric amount of a ternary alloying element X (cf. Table 1) were processed. The Fe-C-X alloys were cast, hot rolled and subsequently austenitized at $1250^{\circ} \mathrm{C}$ for 10 minutes followed by a brine water quench. This first condition will be referred to as as-Q. Next, also a tempering treatment of $1 \mathrm{~h}$ was applied to introduce carbides in the martensitic microstructure. Secondary hardening due to the precipitation of carbides was optimal at $600^{\circ} \mathrm{C}$ for the $\mathrm{Fe}-\mathrm{C}-\mathrm{Ti}, \mathrm{Fe}-\mathrm{C}-\mathrm{Mo}$ and $\mathrm{Fe}-\mathrm{C}-\mathrm{V}$ alloys and at $550^{\circ} \mathrm{C}$ for the Fe-C-Cr material [24-27]. This second condition will be referred to as Q\&T. The microstructure were studied by optical microscopy, SEM and TEM and the degree of $\mathrm{H}$ induced mechanical degradation, the $\mathrm{H}$ content and TDS measurements were determined as described in [24-27]. The \% HE index was determined as:

$$
\% H E=100 \cdot\left(1-\frac{\varepsilon_{c h}}{\varepsilon_{u n}}\right)
$$

with $\varepsilon_{\mathrm{ch}}$ and $\varepsilon_{\mathrm{un}}$ being the elongation of the charged and uncharged sample, respectively. Hence, the $\% \mathrm{HE}$ varies between 0 and 1 , with 0 meaning that there is no ductility loss and the material is insensitive to HE. When an index of 1 is obtained, the ductility drop is $100 \%$ and $\mathrm{HE}$ is maximal.

Table 1: Chemical compositions of the Fe-C-X materials.

\begin{tabular}{|l|l|l|l|}
\hline Alloy Fe-C-X & wt.\% C & wt. \% X & Other elements \\
\hline Fe-C-Ti & 0.313 & 1.34 & $\begin{array}{l}\text { Al: 200-300 wt. ppm } \\
\text { Other elements: traces }\end{array}$ \\
\cline { 1 - 3 } Fe-C-Cr & 0.184 & 2.20 & \\
\cline { 1 - 3 } Fe-C-Mo & 0.177 & 2.99 & \\
\cline { 1 - 3 } Fe-C-V & 0.286 & 1.67 & \\
\hline
\end{tabular}

\section{MATERIALS CHARACTERIZATION}

Optical microscopy showed a clear martensitic and Q\&T microstructure. TEM bright field images are presented in Fig. 1, and displayed small carbides with sizes less than $10 \mathrm{~nm}$ for the Ti- and V-alloy and coarser precipitates for the Moand Cr-alloy. More microstructural details can be found elsewhere [24-27].

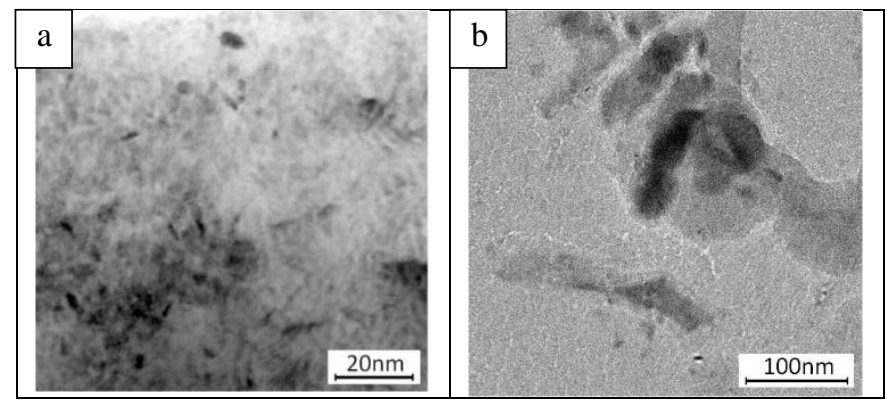




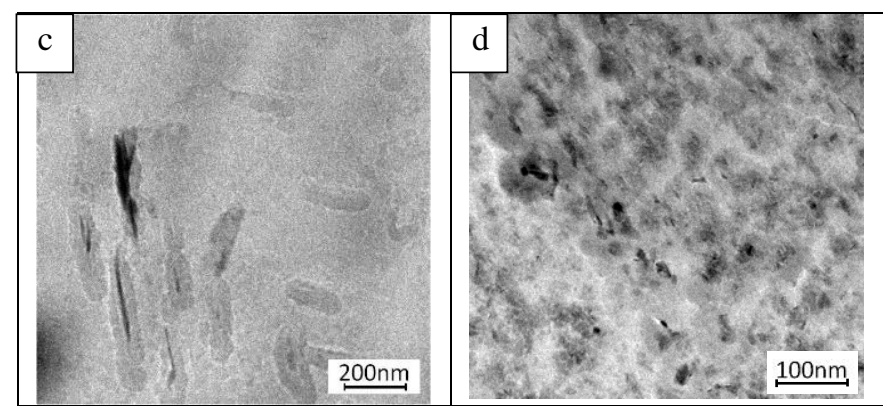

Figure 1: TEM bright field images of $\mathrm{X}$-based carbides of the Fe-C-X alloys in Q\&T condition, with $X=T i(a), C r(b), M o(c)$ and $V(d)$.

\section{RESULTS AND DISCUSSION}

The stress-strain curves for Ti-, Cr-, Mo- and V-alloy in the as-Q and Q\&T condition are depicted in Fig. 2 and the degree of HE is given in Table 2. A significantly different HE susceptibility was observed for the four alloys.
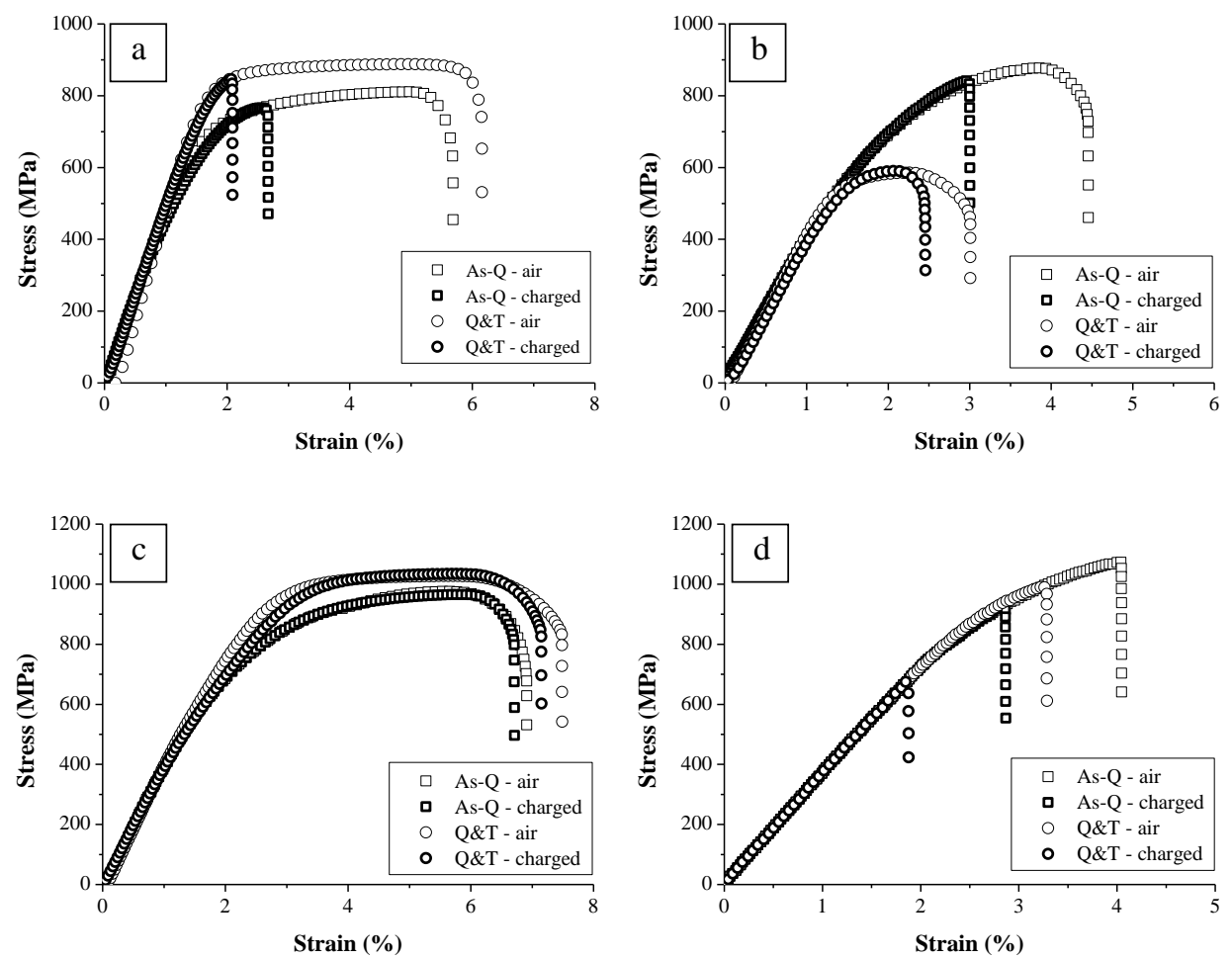

Figure 2: Stress-strain curves for (a) Fe-C-Ti, (b) Fe-C-Cr, (c) Fe-C-Mo and (d) Fe$\mathrm{C}-\mathrm{V}$ at a cross-head deformation speed of $5 \mathrm{~mm} / \mathrm{min}$ of uncharged and $\mathrm{H}$ saturated samples. 
Table 2: The HE indices ( $\% \mathrm{HE}$ ) of $\mathrm{Fe}-\mathrm{C}-\mathrm{X}$ alloys in the as-Q and Q\&T conditions.

\begin{tabular}{|c|c|c|c|c|c|c|c|c|}
\hline \multirow{2}{*}{$\%$ HE } & \multicolumn{2}{|c|}{ Fe-C-Ti } & \multicolumn{2}{c|}{ Fe-C-Cr } & \multicolumn{2}{c|}{ Fe-C-Mo } & \multicolumn{2}{|c|}{ Fe-C-V } \\
\cline { 2 - 9 } & As-Q & Q\&T & As-Q & Q\&T & As-Q & Q\&T & As-Q & Q\&T \\
\cline { 2 - 9 } & 53 & 66 & 33 & 18 & 3 & 5 & 29 & 43 \\
\hline
\end{tabular}

To elaborate these results, hot $\left(\right.$ at $300^{\circ} \mathrm{C}$ ) and melt (at $1600^{\circ} \mathrm{C}$ ) extraction, which shows the diffusible and total $\mathrm{H}$ content of the $\mathrm{H}$ saturated samples, are given in Fig. 3. For the Fe-C-Ti and Fe-C-V materials, the diffusible and total $\mathrm{H}$ content nearly or more than doubled when the sample was tempered. Consequently, the microstructural changes that occurred during tempering, mainly the formation of a considerable amount of small $\mathrm{Ti}$ or $\mathrm{V}$-carbides, provided an important increase in $\mathrm{H}$ trapping sites in the material (cf. TDS results). The Mo- and Cr-alloys showed a significantly lower $\mathrm{H}$ content, while the amount of diffusible $\mathrm{H}$ was the lowest for the Fe-C-Mo alloy. Moreover, the difference between as-Q and Q\&T was also rather small, especially for Fe-C-Cr. Although tempering induced significant microstructural changes as well and therefore, also in the potential trapping sites, the $\mathrm{H}$ trapping capacity of both conditions appeared to be similar.

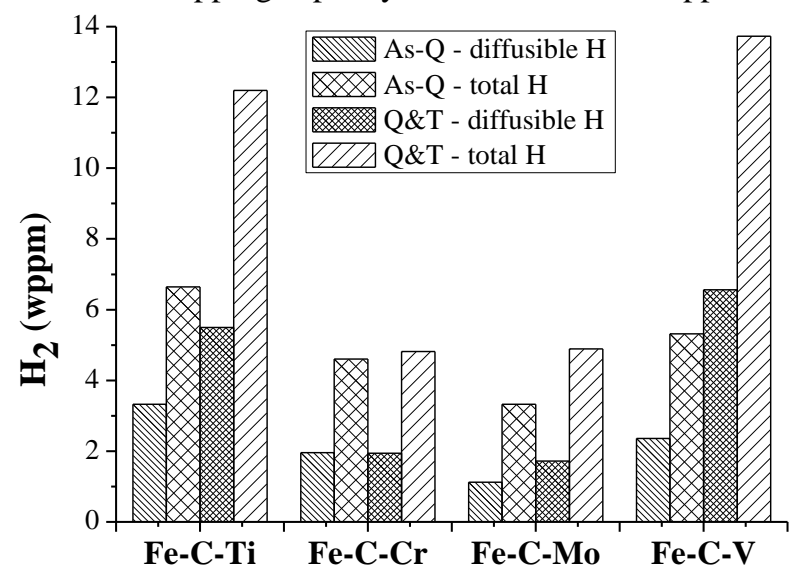

Figure 3: Diffusible and total $\mathrm{H}$ content for saturated $\mathrm{Ti}$-, $\mathrm{Cr}$-, $\mathrm{Mo}$ - and $\mathrm{V}$-alloys in the as- $Q$ and $Q \& T$ condition.

TDS was performed on all Fe-C-X alloys in both the as-Q and Q\&T condition as summarized in Fig. 4. Basically, the first peak can be correlated to $\mathrm{H}$ trapped by lath boundaries, while the other peaks are linked to $\mathrm{H}$ trapped by the carbides. A more detailed interpretation of these data including Ea can be found elsewhere [24-27]. An overview of the $\mathrm{H}$ contents is given in Table 3. There is a clear difference between the amount of $\mathrm{H}$ as determined by hot extraction, i.e. diffusible $\mathrm{H}$, and the total area under the TDS curve. Indeed, $\mathrm{H}$ was able leave the sample before the TDS measurement. This type of $\mathrm{H}$ will be defined as mobile H [24-27]. As demonstrated [19], traps such as dislocations indeed trap $\mathrm{H}$, but loose it before the measurement started, as it took about $1 \mathrm{~h}$ to reach a sufficiently low vacuum in the TDS chamber. During the tensile tests, however, 
this mobile $\mathrm{H}$ is still present and relevant for the obtained results as discussed below.

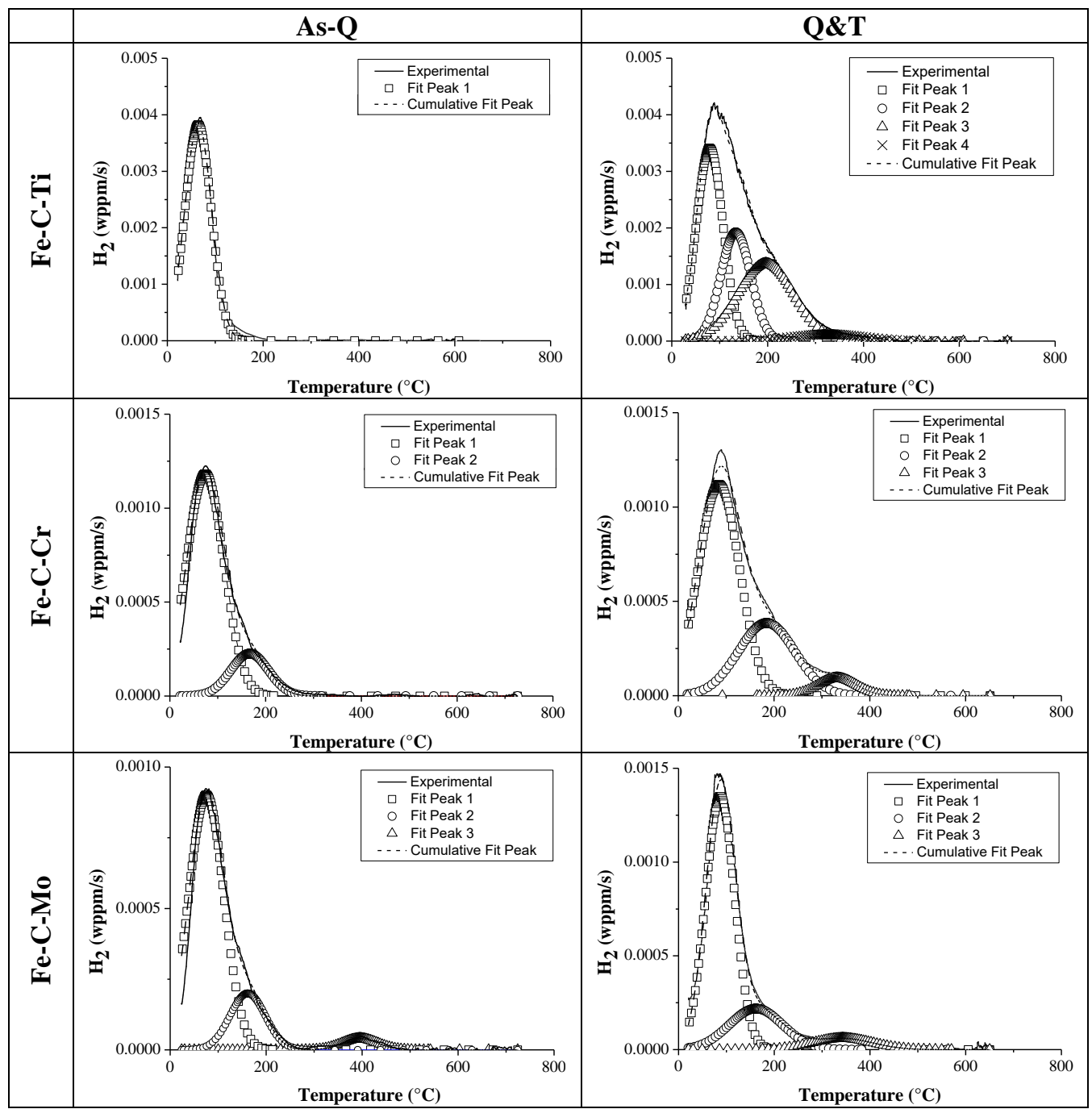



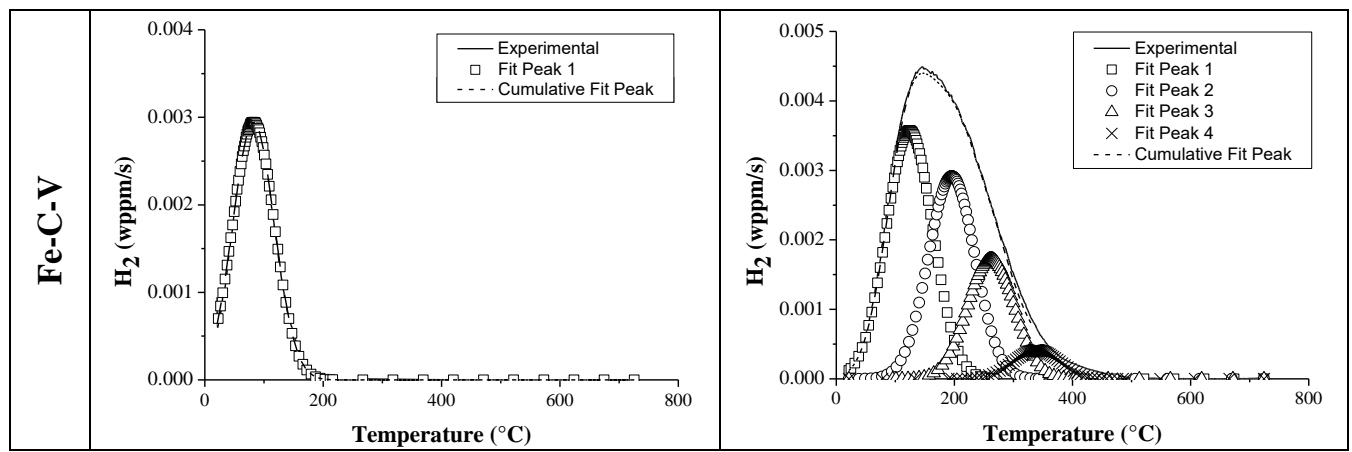

Figure 4: TDS curves of Fe-C-X alloys in the as- $Q$ and $Q \& T$ condition $\left(600^{\circ} \mathrm{C} / \mathrm{h}\right)$.

Table 3: The $H$ contents of the Fe-C-X alloys in the as- $Q$ and $Q \& T$ condition.

\begin{tabular}{|l|c|c|c|c|c|c|c|c|}
\hline $\begin{array}{l}\text { Hydrogen content } \\
\text { (wppm) }\end{array}$ & \multicolumn{2}{|c|}{ Fe-C-Ti } & \multicolumn{2}{|c|}{ Fe-C-Cr } & \multicolumn{2}{c|}{ Fe-C-Mo } & \multicolumn{2}{c|}{ Fe-C-V } \\
\hline diffusible hydrogen & 3.33 & 5.50 & 1.96 & 1.94 & 1.12 & 1.72 & 2.36 & 6.56 \\
\hline hydrogen under TDS & 1.65 & 3.90 & 0.80 & 1.10 & 0.50 & 1.17 & 1.50 & 5.28 \\
\hline mobile hydrogen & 1.68 & 1.79 & 1.16 & 0.89 & 0.68 & 0.61 & 0.86 & 1.75 \\
\hline
\end{tabular}

The HE degree is high (cf. Table 2) for the Fe-C-Ti alloys due to the high amount of $\mathrm{H}$. Additionally, both Ti-alloys contained a similar and high amount of mobile $\mathrm{H}$. Tempering even increased the HE to $66 \%$. This could be attributed to the TiC precipitates formed during tempering, which not only increased the $\mathrm{H}$ trapping capacity as compared to the as-Q samples, but also introduced weakly trapped $\mathrm{H}$ at the elastic stress fields in the matrix surrounding the particle [6, 26]. The as-Q Cr-alloy embrittled more than the Q\&T material although a similar amount of diffusible $H$ was measured. However, due to the trapping ability of the carbides in the Q\&T state, more mobile $\mathrm{H}$ was present in the as-Q material. Consequently, the Q\&T alloy showed a lower HE [24]. The Fe-C-Mo alloys showed a much better resistance to $\mathrm{HE}$, as almost no ductility loss is observed. First of all, the lower $\mathrm{H}$ content can account for this observation. Moreover, the amount of mobile H, was the lowest for this grade [25]. Finally, the $\mathrm{Fe}-\mathrm{C}-\mathrm{V}$ alloys showed rather low strain levels and the $\mathrm{H}$ charged specimen broke in the elastic region of the stress-strain curve. Tempering increased the sensitivity to HE. The higher amount of $\mathrm{H}$, trapped by the $\mathrm{V}$-carbides, can explain this observation. Since no or hardly any plastic deformation occurred for these alloys, the effect of mobile $\mathrm{H}$, trapped at dislocations, is assumed to be minimal [27], as discussed below.

To confirm the hypothesis on the correlation between the HE degree and the amount of mobile $\mathrm{H}$, the relation between the different types of $\mathrm{H}$ (i.e. total, diffusible and mobile) and HE is plotted together with a linear fitting (cf. Fig. 5). The correlation improves for total over diffusible to mobile $\mathrm{H}$. Moreover, when the Fe-C-V materials are excluded, a $\mathrm{R}^{2}$ of $98 \%$ between the $\mathrm{HE} \%$ and the amount of mobile $\mathrm{H}$ is obtained. This confirmed the crucial importance of the 
amount of $\mathrm{H}$ trapped by dislocations and the enhancement of the dislocation mobility by the presence of $\mathrm{H}$ as proposed by the HELP mechanism.

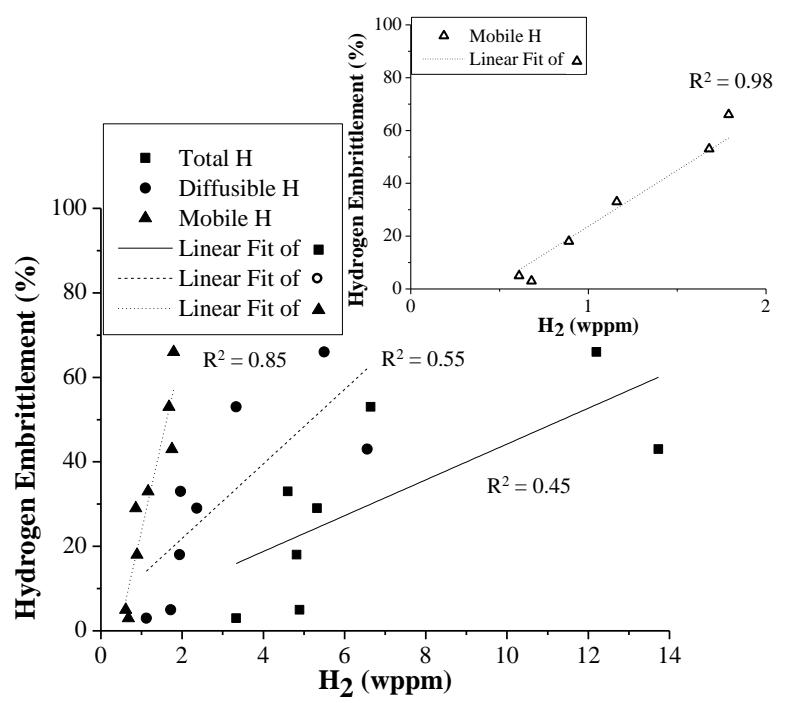

Figure 5: Degree of $\mathrm{HE}$ vs. the total, diffusible and mobile $\mathrm{H}$ content for $\mathrm{Fe}-\mathrm{C}-\mathrm{X}$ alloys. The Fe-C-V alloys were excluded from the data presented in the upper right corner, to illustrate very nicely the correlation between mobile $\mathrm{H}$ and $\mathrm{HE}$ for alloys where the sample broke past the macroscopic yield strength.

\section{CONCLUSIONS}

Four lab cast Fe-C-X materials (with $\mathrm{X}=\mathrm{Ti}, \mathrm{Cr}$, Mo or $\mathrm{V}$ ) were investigated in both as-Q and Q\&T condition. The effect of the present carbides on the $H$ trapping and $\mathrm{HE}$ was evaluated. The tempered induced carbides trapped a significant amount of $\mathrm{H}$. The amount of mobile $\mathrm{H}$, associated with $\mathrm{H}$ trapped at the dislocations, appeared to play a determinant role in the degree of HE. This was nicely illustrated by a correlation between the degree of $\mathrm{HE}$ and the amount of mobile $\mathrm{H}$. The improved relation when the $\mathrm{Fe}-\mathrm{C}-\mathrm{V}$ materials were excluded from the correlation confirmed the importance of an enhanced dislocation mobility in the presence of H, i.e. the HELP mechanism.

\section{ACKNOWLEDGEMENTS}

The authors thank the Special Research Fund (BOF), UGent (BOF10/ZAP/121) and the Agency for Innovation by Science and Technology in Flanders (IWT) for support (Project nr SB111205), V. Bliznuk and E. Wallaert for the TEM images and E. Van den Eeckhout for the permeation experiments. The authors also acknowledge the technicians and staff working at the hydrogen laboratory at ArcelorMittal R\&D Gent and the Department Materials Science and Engineering, UGent, for their help with the experiments and sample preparation. 


\section{REFERENCES}

[1] Vervynckt S, Verbeken K, Lopez B, Jonas JJ, Modern HSLA steels and role of nonrecrystallisation temperature, Int Mat Rev, 57, 187-207, 2012.

[2] Asaoka T, Lapasset G, Aucouturier M, Lacombe P, Observations of $\mathrm{H}$ trapping in Fe-0.15 wt. pct Ti alloy by high resolution autoradiography, Corros NACE, 1978, 39-47, 1978.

[3] Lee HG, Lee JY, H trapping by TiC particles in iron, Acta Met, 32, 131-136, 1984.

[4] Pressouyre GM, Bernstein IM, A quantitative analysis of H trapping, Met Trans A, 9A, 1571-1580, 1978.

[5] Wei FG, Hara T, Tsuzaki K, Precise determination of the $\mathrm{E}_{\mathrm{a}}$ for desorption of $\mathrm{H}$ in two Ti-added steels by a single TDS, Met Mat Trans B, 35B, 587-597, 2004.

[6] Wei FG, Tsuzaki K, Quantitative Analysis on $\mathrm{H}$ trapping of TiC particles in steel, Met Mat Trans A, 37A, 331-353, 2006.

[7] Pérez Escobar D, Wallaert E, Duprez L, Atrens A, Verbeken K, TDS study of the interaction of $\mathrm{H}$ with TiC precipitates, Met Mat Int, 19, 741-748, 2013.

[8] Asahi H, Hirakami D, Yamasaki S, H trapping behavior in V added steel, ISIJ Intl, 43, 527-533, 2003.

[9] Li D, Gangloff RP, Scully JR, H trap states in ultrahigh-strength AERMET 100 steel, Met Mat Trans A, 35, 849-864, 2004.

[10] Spencer GL, Duquette DJ, The role of V carbide traps in reducing the HE susceptibility of high strength alloy steels, Watervliet, N.Y., 1998.

[11] Depover T, Monbaliu O, Wallaert E, Verbeken K, Effect of Ti, Mo and Cr based precipitates on the $\mathrm{H}$ trapping and embrittlement of Fe-C-X Q\&T alloys, Int Journal of H Energy, 40, 16977-16984, 2015.

[12] Hilditch TB, Lee SB, Speer JG, Matlock DK, Response to H Charging in High Strength Automotive Sheet Steel Products, SAE Technical Paper, 2003, http://dx.doi.org/10.4271/2003-01-0525.

[13] Loidl M, HE in HSSs limits use in lightweight body, Adv Mat Process, 169, 22-25, 2011.

[14] Depover T, Pérez Escobar D, Wallaert E, Zermout Z, Verbeken K, Effect of in-situ $\mathrm{H}$ charging on the mechanical properties of advanced high strength steels, Int Journal of H Energy, 39, 4647-4656, 2014.

[15] Ronevich JA, Speer JG, Matlock DK, HE of commercially produced advanced high strength steels, SAE Int Journal Mat Man, 3, 255-267, 2010.

[16] Koyama M, Tasan C, Akiyama E, Tsuzaki K, Raabe D, H-assisted decohesion and localized plasticity in DP, Acta Mat, 70, 174-187, 2014.

[17] Pérez Escobar D, Verbeken K, Duprez L, Verhaege M, Evaluation of H trapping in high strength steels by TDS, Mat Sci and Eng A, 551, 50-58, 2012.

[18] Pérez Escobar D, Miñambres C, Duprez L, Verbeken K, Verhaege M, Internal and surface damage of multiphase steels and pure iron after electrochemical $\mathrm{H}$ charging, Corrosion Science, 53, 3166-3176, 2011.

[19] Pérez Escobar D, Depover T, Wallaert E, Duprez L, Verbeken K, Verhaege M, Combined TDS, DSC, SEM and XRD study of $\mathrm{H}$ trapping in cold deformed TRIP steel, Acta Mat, 60, 2593-2605, 2012.

[20] Depover T, Wallaert E, Verbeken K, Fractographic analysis of the role of $\mathrm{H}$ diffusion on the HE susceptibility of DP steel, Mat Sci and Eng A, 649, 201-208, 
2016.

[21] Laureys A, Depover T, Petrov R, Verbeken K, Characterization of H induced cracking in TRIP-assisted steels, Int Journal of H Energy, 40, 16901-16912, 2015.

[22] Laureys A, Depover T, Petrov R, Verbeken K, Microstructural characterization of H induced cracking in TRIP-assisted steel by EBSD, Materials Characterization, 112, 169-179, 2016.

[23] Wei FG, Hara T, Tsuzaki K, Nano-precipitates design with $\mathrm{H}$ trapping character in high strength steels, in Proc of the Int H Conf, Jackson, Wyoming, 2008.

[24] Depover T, Verbeken K, H trapping and H induced mechanical degradation in lab cast Fe-C-Cr alloys, Mat Sci and Eng A,669, 134-149, 2016.

[25] Depover T, Verbeken K, Evaluation of the role of $\mathrm{Mo}_{2} \mathrm{C}$ in $\mathrm{H}$ induced ductility loss in Q\&T Fe-C-Mo alloys, Int Journal of H Energy, 41, 14310-14329, 2016.

[26] Depover T, Verbeken $\mathrm{K}$, The effect of $\mathrm{TiC}$ on the $\mathrm{H}$ induced ductility loss and trapping behavior of Fe-C-Ti alloys, Corrosion Science, 112, 308-326, 2016.

[27] Depover T, Verbeken K, Evaluation of the effect of $\mathrm{V}_{4} \mathrm{C}_{3}$ precipitates on the $\mathrm{H}$ induced mechanical degradation in Fe-C-V alloys, Mat Sci and Eng A, 675, 299$313,2016$. 